\title{
Expression patterns of cysteine peptidase genes across the Tribolium castaneum life cycle provide clues to biological function
}

Lindsey Perkin, Elena N Elpidina, Brenda Oppert

The red flour beetle, Tribolium castaneum, is a major agricultural pest responsible for considerable loss of stored grain and cereal products worldwide. T. castaneum larvae have a highly compartmentalized gut, with cysteine peptidases mostly in the acidic anterior part of the midgut that are critical to the early stages of food digestion. In previous studies, we described 26 putative cysteine peptidase genes in $T$. castaneum (types $B, L, O, F$, and $K$ ) located mostly on chromosomes 3, 7, 8, and 10. In the present study, we hypothesized that specific cysteine peptidase genes could be associated with digestive functions for food processing based on comparison of gene expression profiles in different developmental stages, feeding and non-feeding. RNA-Seq was used to determine the relative expression of cysteine peptidase genes among four major developmental stages (egg, larvae, pupae, and adult) of $T$. castaneum. We also compared cysteine peptidase genes in T. castaneum to those in other model insects and coleopteran pests. By combining transcriptome expression, phylogenetic comparisons, response to dietary inhibitors, and other existing data, we identified key cysteine peptidases that $T$. castaneum larvae and adults use for food digestion, and thus new potential targets for biologically-based control products. 
1 Expression patterns of cysteine peptidase genes across the Tribolium castaneum life cycle

2 provide clues to biological function

3

4

5 Lindsey C. Perkin ${ }^{1 \S}$, Elena N. Elpidina ${ }^{2}$, and Brenda Oppert ${ }^{1}$

6

7

$8{ }^{1}$ USDA, Agricultural Research Service, Center for Grain and Animal Health Research, 1515

9 College Avenue, Manhattan KS 66502

10

$11{ }^{2}$ A. N. Belozersky Institute of Physico-Chemical Biology, Moscow State University, Moscow

12119991 Russia

13

14 Running title: Cysteine peptidase gene expression in Tribolium castaneum

15

16 §Corresponding author:

17 Email addresses:

18 LCP: lindsey.perkin@ars.usda.gov

19 ELN: elp@belozersky.msu.ru

20 BO: brenda.oppert@ars.usda.gov 


\section{Abstract}

25

The red flour beetle, Tribolium castaneum, is a major agricultural pest responsible for

27 considerable loss of stored grain and cereal products worldwide. T. castaneum larvae have a

28 highly compartmentalized gut, with cysteine peptidases mostly in the acidic anterior part of the

29 midgut that are critical to the early stages of food digestion. In previous studies, we described 26

30 putative cysteine peptidase genes in $T$. castaneum (types $\mathrm{B}, \mathrm{L}, \mathrm{O}, \mathrm{F}$, and $\mathrm{K}$ ) located mostly on

31 chromosomes $3,7,8$, and 10 . In the present study, we hypothesized that specific cysteine

32 peptidase genes could be associated with digestive functions for food processing based on

33 comparison of gene expression profiles in different developmental stages, feeding and non-

34 feeding. RNA-Seq was used to determine the relative expression of cysteine peptidase genes

35 among four major developmental stages (egg, larvae, pupae, and adult) of T. castaneum. We also

36 compared cysteine peptidase genes in T. castaneum to those in other model insects and

37 coleopteran pests. By combining transcriptome expression, phylogenetic comparisons, response

38 to dietary inhibitors, and other existing data, we identified key cysteine peptidases that $T$.

39 castaneum larvae and adults use for food digestion, and thus new potential targets for

40 biologically-based control products. 
42 Introduction

43

44 Tribolium castaneum, the red flour beetle, is a highly destructive stored product pest, and cases

45 of resistance to most control products have been identified (Mann et al., 2013). The T. castaneum

46 genome has been sequenced (Tribolium Genome Sequencing Consortium, 2008), providing a

47 convenient model system to develop and evaluate alternative control strategies for coleopteran

48 storage pests based on genetic analysis. Our previous biochemical and genetic studies have

49 focused on the T. castaneum larval gut, as it is one of the main interfaces between the beetle and

50 the environment. The larval gut of T. castaneum is compartmentalized, with an acidic anterior

51 portion that secretes a high concentration of $\mathrm{C} 1$ family cysteine peptidases, while the slightly

52 alkaline posterior portion of the midgut has mostly serine peptidases (Prabhakar et al., 2007;

53 Vinokurov et al., 2009). The presence of cysteine peptidases in the coleopteran gut has been

54 proposed as an adaptation to avoid serine peptidase inhibitors in grain kernels (Terra \& Ferreira,

55 1994; Terra \& Cristofoletti, 1996; Vinokurov et al., 2009). Cysteine peptidases also provide

56 efficient digestion of cereal grain proteins (Goptar et al., 2012). T. castaneum larvae respond to

57 cysteine peptidase inhibitors through a complex response, increasing the transcript expression of

58 genes encoding specific serine and cysteine peptidases (Oppert et al., 1993, 2003, 2005, 2010).

60 Cysteine peptidases from the $\mathrm{C} 1$ family are mostly found in lysosomes/endosomes in other

61 organisms, but also can be located in other cellular compartments (Turk et al., 2012). Cysteine

62 peptidases are active and stable at slightly acidic $\mathrm{pH}$ and are mostly irreversibly inactivated at

63 neutral $\mathrm{pH}$, which serves as a regulator of activity (Turk et al., 1995). In lysosomes, cysteine

64 peptidases and other hydrolases degrade proteins, activate granule proteases, and participate in

65 cellular processes like antigen presentation (Turk et al., 2012). However, cysteine peptidases also 
66 may be found extracellularly in a variety of tissues, and are involved in many biological

67 processes, such as bone remodeling, keratinocyte differentiation, and prohormone activation.

68 Cysteine peptidases have been implicated in human diseases, like cancer, arthritis, cardiovascular

69 disease and others (Repnik et al., 2012). Activation of cysteine peptidase zymogens occurs when

70 the proenzyme enters an intracellular compartment, such as the lysosome, or is released into an

71 acidic extracellular environment. In vitro, the released propeptide domain can inhibit the activity

72 of the mature enzyme (Coulombe et al., 1996), but cysteine peptidases mostly are regulated by

73 their environment in vitro (i.e., $\mathrm{pH}$ ) or endogenous inhibitors, such as cystatins, thyropins, and

74 others (Turk et al., 2012).

76 In the $T$. castaneum genome, 25 cysteine peptidase genes and one associated pseudogene have

77 been identified (Tribolium Genome Sequencing Consortium et al., 2008; Martynov et al., 2015),

78 more than three times the number of cysteine peptidase genes in Drosophila melanogaster and

79 other current model insects. T. castaneum cysteine peptidase genes include cathepsin B and L

80 peptidases, mostly arranged in clusters on chromosome 3, 7, 8 and 10, and also single genes

81 encoding cathepsins $\mathrm{F}$, $\mathrm{K}$, and $\mathrm{O}$ on chromosome 7, 4 and $1(\mathrm{X})$, respectively. Empirical evidence

82 of the biological function of each cysteine peptidase gene in T. castaneum is lacking, although

83 our previous studies suggest that some function as major processors of food proteins in the larval

84 gut (Oppert et al., 1993; Vinokurov et al., 2009; Oppert et al., 2010; Martynov et al., 2015). Gene

85 expression studies indicated that cathepsin L genes LOC659441 and LOC659502 are the most

86 highly expressed cysteine peptidases in the larval gut and are most likely encoding enzymes

87 important in the early stages of cereal protein digestion, as they are located in the anterior midgut

88 (Prabhakar et al., 2007; Morris et al., 2009; Vinokurov et al., 2009; Martynov et al., 2015). 
90 In the current study, we coupled existing knowledge of $T$. castaneum larval gut cysteine

91 peptidases with new RNA-seq data from the four major life stages. We hypothesized that

92 cysteine peptidase genes highly expressed during feeding stages (adults and larvae) are primarily

93 for food digestion, especially those that coincide with high expression in the larval gut, while

94 those constitutively expressed in all life stages are involved in other life processes. We also

95 compared $T$. castaneum cysteine peptidase genes to those in other model insects and

96 coleopterans. The combined data has allowed us to propose a model of cysteine peptidase

97 function in T. castaneum.

99 Methods

100 Insects

101 The T. castaneum lab colony originated from a grain bin in Kansas more than 30 years ago, and

102 has been reared continuously at the Center for Grain and Animal Health Research (CGAHR,

103 Agricultural Research Service, United States Department of Agriculture, Manhattan, KS, USA)

104 on a diet of $95 \%$ wheat flour and $5 \%$ brewer's yeast at $28^{\circ} \mathrm{C}, 75 \%$ R.H., 0L:24D. For this

105 experiment, insects were subcultured from the laboratory colony, and specific life stages were

106 removed as described. Adults were collected at 3-7 days post-eclosion to ensure they were

107 actively feeding and sexually mature. Eggs were sifted out of diet 24-48 hours after oviposition

108 and were separated from the fine particulate with a brush. Larvae were collected at a late instar

109 stage that was actively feeding (approximately 14 days post hatch). Pupae were sifted out and

110 sorted to include those with pigmentation in the eye, but not the elytra. All stages were sampled

111 from different generations to provide three independent biological samples per life stage. 
113 Library preparation and sequencing

114 RNA was collected from each of the three biological replicates of each life stage (10 adults,

115 approximately 500 eggs, 10 larvae, and 10 pupae per replicate). All samples were pulverized in

116 TRIZOL (BulletBlender, Next Advance Inc., Averill Park, NY, USA) at speed 8 for 2 min with

117 RNAse-free ziroconium oxide beads. RNA extraction and purification was with a Zymo mini

118 prep kit (Irvine, CA, USA). To obtain mRNA, DIRECTbeads (Agilient, Santa Clara, CA, USA)

119 were used to select polyA RNA, and libraries were made with the 200 base pair RNA-seq v2 kit

120 (Life Technologies, Grand Island, NY, USA). Samples were sequenced on 318v2 chips on the

121 Ion Torrent Personal Genome Machine (PGM) (Life Technologies). Each run provided

122 approximately 1-5 million reads, with a total of 5-12 million reads per life stage (Supplemental

123 Table S1).

124

125 Data analysis

126 Data was analyzed using ArrayStar (Lasergene Genomics Suite v12.0.0, DNASTAR, Madison,

127 WI, USA) by mapping reads to the Tcas3 genome build. Read counts were normalized by Reads

128 Per Kilobase of template per Million mapped reads (RPKM (Mortazavi et al., 2008)). A Kruskal-

129 Wallis test was done among the life stages $(\mathrm{df}=3)$, calculated from linear total RPKM values.

130

131 Sequence alignments were made with ClustalW (Thompson et al., 1994), and phylogenetic tree

132 construction using Maximum Likelihood analysis with 500 bootstrapping iterations was with

133 MEGA (Tamura et al., 2013). Predicted protein sequences were used to construct the $T$.

134 castaneum cysteine peptidase gene tree. Nucleotide sequences were used for the model insect 
135 phylogenetic tree, comparing sequences from T. castaneum to those from the models Apis

136 mellifera and Drosophila melanogaster. Sequences were obtained via NCBI gene search, using

137 conserved domain 'peptidase_C1A' (cd02248) as the search criteria for each model species.

138 Nucleotide sequences also were used for the phylogenetic comparison of coleopteran pest

139 cysteine peptidase genes in T. castaneum, Dendroctonus ponderosae, Diabrotia virgiferi

140 virgiferi and Leptinotarsa decemlineata. The other coleopteran insects did not have fully

141 annotated genomes at the time of this analysis, so to find all genes identified as cysteine

142 peptidases, NCBI nucleotide BLAST was used (Altschul et al., 1990) with the following search

143 strategy. First, T. castaneum LOC659441 was used as the query sequence, and search results

144 were limited to the three coleopteran pests of interest. Second, T. castaneum LOC663234 was

145 used as the query sequence and results were limited as before. The second BLAST did not return

146 any new sequences, indicating we had retrieved all possible gene sequences deposited in NCBI

147 using the first sequence. All trees used T. castaneum LOC655494 (aspartic protease) as a rooted 148 outgroup.

150 Comparisons between D. melanogaster and T. castaneum gut cysteine peptidase expression were 151 made using FlyAtlas Anatomical Expression Data (FlyAtlas.org; Robinson et al., 2013). Levels

152 of expression were determined using default parameters in FlyAtlas (no expression = 0-9.999

153 RPKM, low expression $=10-99.999$ RPKM, moderate expression $=100-499.999$ RPKM, high

154 expression $=500-999.999$ RPKM, and very high expression $>999.999$ RPKM).

156 Results and Discussion

157

158 Overall cysteine peptidase expression patterns 
159 The relative expression of $T$. castaneum cysteine peptidase genes in different developmental

160 stages was obtained by high throughput sequencing of the transcriptome of three independent

161 biological replicates obtained from adults, eggs, larvae, and pupae (Table 1, Supplemental Table

162 S2). Overall, specific cathepsin L and B transcripts were more abundant in the feeding stages

163 (adult and larvae), and overlapped with those previously identified in a larval gut study (Morris

164 et al., 2009) or in response to dietary inhibitors (Oppert et al., 2010). Both classical cathepsin B

165 peptidases and atypical cathepsin B-like peptidases with a shortened occluding loop were found

166 in T. castaneum (Martynov et al., 2015). The expression patterns of cathepsin B peptidase genes

167 from either classical or atypical groups were similar among the different life stages, but the

168 expression levels of the atypical cathepsin B-like peptidase genes were lower overall than

169 classical cathepsin B genes. Cathepsin F and O peptidase genes were expressed in all life stages,

170 but differed in relative expression levels in pupae (5.3 RPKM vs. 115 RPKM, respectively).

171 Some cysteine cathepsin genes were not expressed in any life stage (or were weakly expressed);

172 cathepsin K was expressed weakly only in adults. Many cathepsin B and B-like genes, one

173 cathepsin $\mathrm{L}$ gene, and cathepsin $\mathrm{F}$ and $\mathrm{O}$ genes were predicted to be lysosomal enzymes in their

174 NCBI entries (Table 1, shaded). We also noted that two cathepsin L genes (LOC659226 and

175 LOC659367) and a cathepsin B-like gene (LOC655148) were no longer supported gene models

176 at NCBI at the time of this publication, but the current and previous data analyses included these 177 genes.

178

179 Differential expression patterns of the RNA-Seq data were more easily discernible in a heat map

180 of gene expression across the T. castaneum life cycle (Fig. 1). Blocks of color within the heat

181 map highlighted three main patterns: (1) increased expression during adult and larval stages 
182 relative to pupae and eggs (yellow to red in contrast to blue to grey in other stages, herein

183 referred to as pattern group one), (2) constitutive expression across all stages (yellow to orange

184 in all stages, herein referred to as pattern group two), and (3) low to no expression across all

185 stages (blue to grey in all stages, herein referred to as pattern group three).

186

187 Pattern group one included 12 genes encoding cathepsin L or B cysteine peptidases (Fig. 2A).

188 Similar to our previous data from the larval gut (Morris et al., 2009; Martynov et al., 2015), we

189 observed that three cathepsin L genes, LOC659441 and LOC659502 on chromosome 10, and

190 LOC660368 on chromosome 7, were the most highly expressed cysteine peptidase genes among

191 all of the developmental profiles in T. castaneum (Table 1). These genes were primarily

192 expressed in larvae and adults, and the difference in expression across developmental stages was

193 significant (Kruskal-Wallis test, $\mathrm{p}<0.05$; Table S2). The most highly expressed cathepsin B

194 peptidase gene in adults and larvae was LOC663145 on chromosome $3(p<0.03)$. Other genes in 195 pattern group one with lower expression levels encoded cathepsin L (LOC660669), cathepsin B 196 (LOC663117 and LOC663090), cathepsin B-like (LOC655148, LOC656957 and LOC657203), 197 and L and B homologs (LOC659367 and LOC657117, respectively). Homologs lack conserved 198 residues of typical cathepsins. We propose that members of this pattern group have some role in 199 dietary protein digestion, as they are most abundant during feeding stages.

201 Pattern group two was comprised of a suite of six genes constitutively expressed across all life 202 stages, albeit at overall lower levels than the previous group (Fig. 2B). Genes displaying this 203 expression pattern included cathepsin L (LOC659226, LOC663234), cathepsin B-like

204 (LOC663066), cathepsin B homolog (LOC656198), cathepsin F (LOC662417), and cathepsin O 
205 (LOC659087). Although expressed in all stages, one cathepsin L (LOC663234) and cathepsin O 206 (LOC659087) were expressed much higher in pupae (Table 1). We hypothesized that these

207 constitutively expressed genes are not involved in food digestion but in other life processes, and 208 probably are secreted to the lysosome.

210 Pattern group three contained eight cysteine peptidase genes with little or no expression across

211 all stages (Fig. 2C). Genes in this group included cathepsin L (LOC659565, LOC660428,

212 LOC660551, LOC658343), cathepsin B-like (LOC655077, LOC657038), cathepsin K

213 (LOC100141668), and a pseudogene (LOC660491). While these genes may be considered

214 "minor" cysteine cathepsins by their expression levels, we did find differential expression among

215 developmental stages for some (LOC659565, LOC660428, LOC100141668), suggesting they

216 may have stage-specific roles. However, some of these genes may be vestigial, evolutionary

217 remnants of cysteine peptidase genes.

218

219 Interestingly, genes encoding homologs that lack conservation in critical amino acid residues for 220 cysteine peptidase function displayed differential expression patterns. Cathepsin L-homolog 221 (LOC659367) and cathepsin B-homolog (LOC657117) were expressed at higher levels in adult 222 and larvae and were in pattern group one (Fig. 2A). Cathepsin B-homolog (LOC656198; pattern 223 group two) was expressed in all life stages, although considerably lower in pupae (Fig. 2B, Table

224 1). While these peptidases may not have a catalytic role, their expression patterns suggest that 225 they have biological relevance in T. castaneum.

227 Comparison of RNA-Seq to tiling arrays 
228 Tiling array information for developmental stages is available in Beetlebase

229 (http://beetlebase.org/). This information was generated for gene annotation and not for relative

230 expression. However, the tiling array surveyed more time-points in T. castaneum development

231 (6h, 14h, and 30h embryonic; early, mid and late larval; early, mid, and late male and female

232 pupae; early and late male and female adult) and in some cases demonstrated more details about

233 the relative expression profile of some peptidase genes within a developmental stage

234 (Supplemental Figs. S1-S5). Mostly the RNA-Seq and tiling array profiles were similar, with

235 these exceptions in tiling array profiles compared to RNA-Seq data: cathepsin L LOC660669

236 was more highly expressed in embryos (Supplemental Fig. S2); cathepsin B-like LOC655077

237 had increased expression in all stages (Supplemental Fig. S3a); cathepsin L homolog

238 LOC659367 was expressed less in larvae and adult (Supplemental Fig. S4); cathepsins L and K,

239 LOC658343 and LOC100141668, respectively, were expressed more in embryos, and cathepsin

240 B homolog LOC656198 was expressed less in adults (Supplemental Fig. S5). For non-

241 constitutively expressed genes identified in our RNA-Seq study, expression patterns in the tiling

242 array were sometimes cyclical, with increased expression particularly in late embryo, early to

243 mid larval, and throughout adult stages, suggesting the expression was coordinated and regulated

244 (Supplemental Figs. S1-4).

Integration of RNA-Seq and iBeetle phenotypes

247 An RNAi screen at iBeetle (http://ibeetle-base.uni-goettingen.de; Dönitz et al., 2015) documents

248 the phenotypic response of $T$. castaneum after injection with gene-specific dsRNA at the larval

249 and pupal stage. Of the 25 cysteine cathepsins in our study, eight have been analyzed in iBeetle

250 (Supplemental Table S3). In general, knockdown of the B, B-like, and B homolog cathepsins 
251

(LOC663066, LOC663145, LOC656957, LOC656198, LOC663090, LOC657117) had little

252 phenotypic change from wild type and did not cause significant mortality. An exception,

253 cathepsin B homolog LOC656198, had 20\% mortality 22 days post-larval injection, and pupae

254 were unable to eclose.

255

256

257

258

259

260

261

262

263

264

265

266

267

268

269

270

271

272

273

Injection of dsRNA for cathepsin L LOC659226 induced some mortality post larval injection (20-30\%), but interestingly, adults that survived had no living offspring (Supplemental Table S3).

In our study, LOC659226 was constitutively expressed, but lower in pupae, which supports the fact that knockdown during the pupal stage had little or no effect on development or phenotype in iBeetle. LOC659226 was also characterized as pattern group two in this study, and as knockdown in larvae affected fecundity of adults, it may be involved in embryogenesis.

Perhaps the most interesting knockdown was cathepsin L LOC660368, where all beetles injected as larvae died (Supplemental Table S3). Survivorship after pupal injection was much higher (only 10\% mortality), but adults had reduced fecundity due to egg defects. In our study, LOC660368 was highly expressed during larval and adult stages (part of pattern group one) and therefore proposed to be involved in digestion. The data demonstrates that LOC660368 is apparently crucial to beetle survival.

\section{Response of cysteine peptidase gene expression to inhibitors}

Previously, we used microarrays to evaluate the larval gut response to dietary inhibitors E-64 (trans-epoxysuccinyl-L-leucylamido(4-guanidino)butane), a cysteine peptidase inhibitor with broad specificity, and STI (soybean trypsin inhibitor) typically a serine peptidase inhibitor 
274 (Oppert et al., 2010). In that study, we found that highly expressed cathepsin L and B genes in

275 the larval gut (LOC659441, LOC659502, LOC660368, and LOC663145) were increased in

276 expression even more when larvae were fed diets containing peptidase inhibitors (PIs,

277 summarized in Table 1). This response suggests a protective compensation mechanism to retain

278 the expression of these enzymes in larvae. Cathepsin B-like (LOC656957 and LOC657203) and

279 cathepsin B homolog (LOC657117), expressed at low to moderate levels in adult and larval

280 feeding stages in this study, were highly upregulated (from 4 to 20 -fold) when larvae were fed E-

281 64. All of these genes were found in pattern group one of this study, and all of these enzymes are

282 likely important in protecting the insect from the deleterious effects of cysteine peptidase

283 inhibitors through additional compensation mechanisms. Cathepsin L (LOC659565), cathepsin B

284 (LOC663090) and cathepsin B-like (LOC655077, LOC655148, and LOC663066) genes

285 decreased in expression when inhibitors were fed to larvae, even though they were not highly

286 expressed in the control larval gut (Morris et al., 2009) or other life stages (this study). These

287 genes are likely sensitive to the inhibitors and lack a feedback mechanism for upregulation.

288

289 Phylogenetic analysis of $\mathrm{T}$. castaneum cysteine cathepsins

290 We aligned predicted protein sequences (excluding pseudogene LOC660491) and overlaid

291 expression pattern data for a phylogeny of all T. castaneum cysteine peptidases (Fig. 3). Cysteine

292 peptidases clustered into two main clades based on function, cathepsin L and B. In general, most

293 subclades represented either pattern group one (red shading) or pattern group two (yellow

294 shading) with pattern group three genes (blue shading) intercalated within each clade. For

295 example, in clade B, the subclade including LOC657117, LOC657203, LOC656957, and

296 LOC657038 (bottom of the tree) had high sequence similarity, but only three of the four had 
297 increased expression during feeding stages. In clade L, highly expressed genes LOC660368 and

298 LOC660669 were similar to LOC658343 (top of tree), which was expressed at lower levels. The

299 genes expressed at low levels may be acquiring loss of function mutations.

300

301 Genes in pattern group one also grouped mostly by chromosomal location. Clusters of cathepsin

302 L peptidases on chromosome 10 and clusters of cathepsin B and B-like peptidases from

303 chromosome 3 and 8 were found within subclades (Fig. 3). In clades B and L, each chromosome

304 group also included at least one gene with low/no expression. This may be evidence of recent

305 gene duplication events, with some genes retaining functions, while others loose or gain new

306 function and thus have reduced expression compared to their digestive counterparts. LOC660491

307 is annotated in the NCBInr database as a cathepsin L pseudogene and was excluded from the

308 phylogenetic tree. This pseudogene is found on chromosome 7 in a cluster of five cathepsin $\mathrm{L}$

309 genes with varied expression levels, located between LOC660551 and LOC660428, both with

310 low expression in all life stages. However, other cathepsin L genes on chromosome 7 were

311 either highly or constitutively expressed.

312

313 Cathepsin F (LOC662417), K (LOC100141668), and O (LOC659087) peptidase genes are

314 singular representatives from each cysteine peptidase type and cluster together in a subclade,

315 although bootstrap values were very weak (bootstrap $=6$ and 24). Phylogeny demonstrated that

316 they are more similar to cathepsin L genes. Cathepsin F and O genes are constitutively expressed,

317 suggesting an indispensible function across life stages (Table 1).

318

319 Phylogenetic analysis among model insects 
320 A phylogenetic analysis with the model insects Drosophila melanogaster and Apis mellifera

321 showed specific grouping among taxa (Fig. 4). D. melanogaster and A. mellifera have

322 substantially fewer annotated cysteine peptidase genes than T. castaneum, and in several cases a

323 large cluster of highly upregulated T. castaneum genes were lone representatives in a subclade.

324 Highly expressed T. castaneum genes from pattern group one grouped into two subclades, with

325 cathepsin L genes LOC659441 and LOC659502 and L homolog LOC659367 in one subclade

326 (bootstrap =99), and cathepsin L LOC660368 in another subclade (bootstrap = 89) with genes

327 expressed at lower values. Similarly, highly expressed cathepsin B LOC663145 was in a

328 subclade (bootstrap $=99$ ) with other pattern group one genes, as well as constitutively expressed

329 LOC663066 and low expression genes LOC655077 and LOC667038. Putative digestive cysteine

330 peptidases forming unique subclades points to a relatively recent expansion within the $T$.

331 castaneum lineage. These gene duplications may have occurred after the split from Hymenoptera

332 and Diptera, approximately 200-300 million years ago (Misof et al., 2014).

333

334 We can find only a few D. melanogaster and no A. mellifera studies of cysteine peptidase gene

335 function in the literature. Three D. melanogaster cysteine peptidase genes had increased

336 expression in the fly midgut and hindgut (Cp1, VH-very high expression, and 26-29-p, H-high

337 expression, from the cathepsin L group, and CG12163, VH-very high expression from the

338 cathepsin B group) (Fig. 4), as defined by default parameters in FlyAtlas Anatomical Expression

339 Data in larva and adult (FlyBase.org, dos Santos et al., 2015). Interestingly, the T. castaneum

340 ortholog to Cp1 is the pseudogene LOC660491 (bootstrap =48). Therefore, we speculate that

341 LOC660491 is ancestral to the duplicated genes on chromosome 7, but has since evolved as a

342 loss of function pseudogene. D. melanogaster $\mathrm{Cp} 1$ gene was hypothesized to have a role as a 
343 universal housekeeping gene or development because it was expressed in all life stages

344 (Matsumoto et al., 1995). Cp1 was also isolated from a D. melanogaster haemocytic mbn-2 cell

345 line and localized to lysosomes within the cell (Tryselius \& Hultmark, 1997). Cp1 has sequence

346 similarity (68\%) to lobster cysteine proteinase-3, which was found in lobster digestive "juice"

347 and had significant expression in alimentary organs, suggesting a role in digestion in this species

348 (Laycock et al., 1989). Cp1 grouped with other putative non-digestive genes in T. castaneum,

349 indicating that the beetle orthologs also are probably lysosomal.

350

351 In contrast, 26-29-p cathepsin L genes were essentially identical (bootstrap = 99) and highly

352 expressed in the larval gut of both the fly and beetle, as well as in all developmental stages of $T$.

353 castaneum, suggesting a common function in both species. In D. melanogaster, gene 26-29-p is

354 named for the expressed protein molecular mass $(26 / 29 \mathrm{kDa})$ and identification as a "proteinase"

355 (p) (Fujimoto et al., 1999). 26-29-p has a role in insect immunity defense mechanisms and is

356 conserved in a number of insects. T. castaneum 26-29-p was continuously expressed across all

357 life stages and thus also could provide a general immune response. D. melanogaster 26-29-p

358 mutants had enlarged rhabdomeres and ommatidia and therefore a potential role in eye

359 development via apoptosis (Gambis et al., 2011). Thus, 26-29-p may have a ubiquitous role

360 degrading proteins in general processes such as immunity and development.

361

362 D. melanogaster CG12163 had low similarity to T. castaneum LOC662417 (bootstrap = 26), a

363 putative cathepsin $\mathrm{F}$ with constitutive expression across life stages. However, the T. castaneum

364 cathepsin F was nearly identical to A. mellifera LOC408851 (bootstrap =99), suggesting a

365 similar function in these insects, although empirical data is not available. 
367 Phylogenetic analysis among coleopteran pests

368 The coleopteran tree revealed a wide range in the number of cysteine peptidases in selected

369 beetle species available at the time of this study (Fig. 5). Dendroctonus ponderosae had a total of

37053 cysteine peptidases, Leptinotarsa decemlineata had 36 and Diabrotica virgifera virgifera had

371 eight. The lower count in D. virgifera virgifera may be an artifact, due to the lack of a complete

372 genome sequence. The tree did not group by species, but by peptidase type, mainly type L and B,

373 indicating conservation of these enzyme types in coleopterans. In many cases, large groups of

374 genes from a single species clustered together with high sequence similarity (bootstrap values

$375>85$ ). In these cases, the clade was collapsed for ease of reading, and the number of original

376 sequences is shown in parentheses. T. castaneum genes are highlighted to show gene expression

377 patterns as in Fig. 3 and 4. In general, constitutively expressed genes had orthologs in other

378 beetles, while the highly expressed genes in feeding stages appear to be more divergent. Overall,

379 there was evidence of an expansion/duplication of cathepsin L peptidase genes in D. ponderosae

380 and L. decemlineata, whereas expansion of cathepsin B genes was more evident in T. castaneum

381 and $D$. ponderosae.

382

383 The phylogenic analyses illustrated that a few cysteine peptidases are conserved across insects,

384 but after coleopterans branched from other insects, cysteine peptidases duplicated many times,

385 presumably to preserve effective food digestion in a hostile environment of plant antidefense

386 compounds. Duplication led to many genes of similar function, which reduced the selective

387 pressure on an individual gene. Increased expression of cysteine peptidase genes or mutations

388 protected these insects from harmful dietary inhibitors and improved dietary efficiency. We 
389 found evidence of this in tenebrionids, where the substrate binding regions in cysteine peptidases

390 were highly variable (Martynov et al., 2015). These phenomena allowed for the accumulation of

391 mutations and eventually led to loss of function or new function (neofunctionalization). In $T$.

392 castaneum, L. decemlineata, and D. ponderosae, cysteine peptidase genes were greatly expanded

393 in gene duplication events. The expansion in the two field pests (L. decemlineata, and D.

394 ponderosae) appears to be more expansive, probably because of the intense selection pressure

395 these insects incur from a more diverse diet.

397 Development of a functional model for cysteine peptidases in T. castaneum

398 We synthesized all of the evidence thus far into a working model of cysteine peptidase function

399 in T. castaneum (Fig. 6; an alternate figure containing the GLEAN numbers from the original

400 annotation can be found in Supplemental Fig. S6). We concluded the 12 genes in pattern group

401 one have higher expression during feeding stages of $T$. castaneum, and all are potentially

402 involved in food digestion (Fig. 6, genes in red circle not overlapping with other circles). Of

403 those, ten have multiple lines of evidence suggesting involvement in digestion: increased

404 expression during feeding stages (this study), high gut rank in a previous microarray analysis

405 (Morris et al., 2009), high expression in the larval gut in a previous RNA-Seq experiment

406 (Martynov et al., 2015), and in most cases differential expression in response to dietary inhibitors

407 (Oppert et al., 2012; Fig. 6, first ten listed in red circle). These ten include seven cathepsin L and

408 B genes with a major role in digestion, (Fig. 6, underlined) and three with a minor role when fed

409 a normal diet. In a previous biochemical study, we described seven distinct cysteine peptidase

410 activities from fractionation of gut enzymes in the T. castaneum gut, and all were anionic

411 enzymes mostly in the anterior midgut (Vinokurov et al., 2009); we propose that the seven major 
412 cysteine cathepsin digestive genes listed here encode those seven anionic enzymes. Three

413 cathepsin B or B-like genes (LOC657117, LOC657203, and LOC656957) and four cathepsin L

414 genes (LOC659441, LOC659502, LOC660368, and LOC663145) were upregulated when $T$.

415 castaneum larvae were fed digestive inhibitors (Figure 6; asterisk); these genes provide optimal

416 targets to control this damaging stage of the beetle as they apparently provide a compensation

417 response. Two genes in pattern group three with low expression were further reduced

418 (LOC655077 and LOC659565) when fed inhibitors (Fig. 6; overlap with red and blue). One

419 constitutively expressed gene (LOC663066) also decreased when larvae were fed inhibitors

420 (Figure 6; overlap with red and yellow).

421

422 Genes that were constitutively expressed (LOC659226, LOC663234, LOC658087, LOC662417, 423 and LOC656198; Fig. 6, yellow circle) also are potential targets for control via RNAi; while

424 some of these may be lysosomal, lysosomal enzymes have been demonstrated to be amenable to 425 RNAi (Koo et al., 2008). The cysteine peptidase genes that had low to no abundance in any of 426 the developmental stages evaluated in this study (Fig. 6, blue circle), may be expressed at other 427 developmental times than those sampled in this study, in different environments or diets, or at 428 low levels in specific tissues. Alternatively, some may represent genes acquiring loss-of-function 429 mutations, eventually to become additional pseudogenes.

430

431 We also note that comparable expression patterns in both larvae and adults suggest that both

432 stages can be targeted in pest control strategies. LOC659441 and LOC659502 were the most

433 highly expressed among all cysteine peptidase genes in adults and larvae. Expression was higher 434 in larvae than in adults (15-fold and 2-fold increased expression, respectively), suggesting that 
435 larvae are more efficient in dietary protein hydrolysis and would be the more economically

436 damaging stage. However, larvae persist approximately 30 days, whereas adults can live up to

437 two years, and they may be more easily targeted with biopesticides. Additionally, targeting

438 individual genes that are part of a group with similar function and compensation mechanism may

439 not be effective. Therefore, more unique cysteine cathepsins might be better genetic targets. The

440 phenotypic data from the iBeetle RNAi screen indicated that targeting LOC6630368 and

441 LOC659226 at the larval stage resulted in no living offspring, suggesting either gene could be an

442 excellent candidate for oral RNAi pest control methods.

443

444 Conclusions

445 We found that developmental expression profiles provided clues to the function of individual

446 cysteine peptidase genes in T. castaneum. When we combined the data with previous studies as

447 well as phylogenetic studies, we found considerable evidence that coleopteran cysteine peptidase

448 genes have duplicated and evolved in response to selection pressure, and are continuing to do so

449 for improved digestion. This information will be useful in understanding and characterizing the

450 expanded cysteine peptidase gene family in $T$. castaneum and in other beetles. A greater

451 understanding of digestion and peptidase activity across the life cycle of this pest species will be

452 useful in the development of new pest control products and strategies.

453

454 Acknowledgements

455 We would like to thank Tom Morgan for help maintaining and collecting insects. Mention of 456 trade names or commercial products in this publication is solely for the purpose of providing 
457 specific information and does not imply recommendation or endorsement by the U.S.

458 Department of Agriculture. USDA is an equal opportunity provider and employer. 
460

461

462

463

464

465

466

467

468

469

470

471

472

473

474

475

476

477

478

479

480

481

482

483

484

485

486

487

488

489

490

491

492

493

494

495

496

497

498

499

500

501

502

503

504

505

$\underline{\text { References }}$

Altschul SF, Gish W, Miller W, Myers EW, and Lipman DJ. 1990. Basic local alignment search tool. Journal of Molecular Biology:403-410.

Coulombe R, Grochulski P, Sivaraman J, Menard R, Mort J, and Cygler M. 1996. Structure of human procathepsin L reveals the molecular basis of inhibition by the prosegment. The EMBO journal 15:5492.

Dönitz J, Schmitt-Engel C, Grossmann D, Gerischer L, Tech M, Schoppmeier M, Klingler M, and Bucher G. In revision. iBeetle-Base: a database for RNAi phenotypes in the red flour beetle Tribolium castaneum. Nucleic Acid Research.

Dos Santos G, Schroeder AJ, Goodman JL, Strelets VB, Crosby MA, Thurmond J, Emmert DB, Gelbart WM; the FlyBase Consortium. 2015. FlyBase: Introduction of the Drosophila melanogaster Release 6 reference genome assembly and large-scale migration of genome annotations. Nucleic Acids Research.

Fujimoto Y, Kobayashi A, Kurata S, and Natori S. 1999. Two subunits of the insect 26/29-kDa proteinase are probably derived from a common precursor protein. Journal of Biochemistry 125:566-573.

Gambis A, Dourlen P, Steller H, and Mollereau B. 2011. Two-color in vivo imaging of photoreceptor apoptosis and development in Drosophila. Developmental Biology 351:128-134.

Goptar I, Semashko T, Danilenko S, Lysogorskaya E, Oksenoit E, Zhuzhikov D, Belozersky M, Dunaevsky Y, Oppert B, and Filippova IY. 2012. Cysteine digestive peptidases function as post-glutamine cleaving enzymes in tenebrionid stored-product pests. Comparative Biochemistry and Physiology Part B 161:148-154.

Hagstrum DW, Phillips TW, and Cuperus G. 2012. Stored Product Protection. Manhattan, KS: Kansas State University.

Jagadeesan R, Collins PJ, Daglish GJ, Ebert PR, and Schlipalius DI. 2012. Phosphine resistance in the rust red flour beetle, Tribolium castaneum (Coleoptera: Tenebrionidae): inheritance, gene interactions and fitness costs. PLoS One 7:e31582.

Koo IC, Ohol YM, Wu P, Morisaki JH, Cox JS, Brown EJ. 2008. Role for lysosomal enzyme beta-hexosaminidase in the control of mycobacteria infection. Proceedings of the National Academy of Sciences USA. 105:710-715.

Laycock MV, Hirama, T, Watson D, and Storer C. 1989. Purification and characterization of a digestive cysteine proteinase from the American lobster (Homarus americanus). Biochemical Journal 263:439-444.

Mann J, Adam BD, and Arthur F. 2013. Stored-grain insect control costs in varying climates and levels of insects' phosphine resistance. 2013 Annual Meeting, August 4-6, 2013, Washington, DC: Agricultural and Applied Economics Association.

Martynov AG, Elpidina EN, Perkin L, and Oppert B. 2015. Functional analysis of C1 family cysteine peptidases in the larval gut of Tenebrio molitor and Tribolium castaneum. BMC Genomics 16:75.

Matsumoto I, Watanabe H, Abe K, Arai S, and Emori Y. 1995. A putative digestive cysteine proteinase from Drosophila melanogaster is predominantly expressed in the embryonic and larval midgut. European Journal of Biochemistry 227:582-587.

Misof B, Liu SL, Meusemann K, Peters RS, Donath A, Mayer C, Frandsen PB, Ware J, Flouri T, Beutel RG, Niehuis O, Petersen M, Izquierdo-Carrasco F, Wappler T, Rust J, Aberer AJ, 
506

507

508

509

510

511

512

513

514

515

516

517

518

519

520

521

522

523

524

525

526

527

528

529

530

531

532

533

534

535

536

537

538

539

540

541

542

543

544

545

546

547

548

549

550

Aspock U, Aspock H, Bartel D, Blanke A, Berger S, Bohm A, Buckley TR, Calcott B, Chen JQ, Friedrich F, Fukui M, Fujita M, Greve C, Grobe P, Gu SC, Huang Y, Jermiin LS, Kawahara AY, Krogmann L, Kubiak M, Lanfear R, Letsch H, Li YY, Li ZY, Li JG, Lu HR, Machida R, Mashimo Y, Kapli P, McKenna DD, Meng GL, Nakagaki Y, Navarrete-Heredia JL, Ott M, Ou YX, Pass G, Podsiadlowski L, Pohl H, von Reumont BM, Schutte K, Sekiya K, Shimizu S, Slipinski A, Stamatakis A, Song WH, Su X, Szucsich NU, Tan MH, Tan XM, Tang M, Tang JB, Timelthaler G, Tomizuka S, Trautwein M, Tong XL, Uchifune T, Walzl MG, Wiegmann BM, Wilbrandt J, Wipfler B, Wong TKF, Wu Q, Wu GX, Xie YL, Yang SZ, Yang Q, Yeates DK, Yoshizawa K, Zhang Q, Zhang R, Zhang WW, Zhang YH, Zhao J, Zhou CR, Zhou LL, Ziesmann T, Zou SJ, Li YR, Xu X, Zhang Y, Yang HM, Wang J, Kjer KM, Zhou X. 2014. Phylogenetics resolves the timing and pattern of insect evolution. Science 6210:763-767.

Morris K, Lorenzen MD, Hiromasa Y, Tomich JM, Oppert C, Elpidina EN, Vinokurov K, JuratFuentes JL, Fabrick J, and Oppert B. 2009. Tribolium castaneum Larval Gut Transcriptome and Proteome: A Resource for the Study of the Coleopteran Gut. Journal of Proteome Research 8:3889-3898.

Mortazavi A, Williams BA, McCue K, Schaeffer L, and Wold B. 2008. Mapping and quantifying mammalian transcriptomes by RNA-seq. Nature Methods 5:621-628.

Nakakita H, and Winks RG. 1981. Phosphine resistance in immature stages of a laboratory selected strain of Tribolium castaneum (Herbst) (Coleoptera: Tenebrionidae). Journal of Stored Products Research 17:43-52.

Opit GP, Phillips TW, Aikins MJ, and Hasan MM. 2012. Phosphine resistance in Tribolium castaneum and Rhyzopertha dominica from stored wheat in Oklahoma. Journal of Economic Entomology 105:1107-1114.

Oppert B, Elpidina EN, Toutges M, and Mazumdar-Leighton S. 2010. Microarray analysis reveals strategies of Tribolium castaneum larvae to compensate for cysteine and serine protease inhibitors. Comparative Biochemistry and Physiology 5D:280-287.

Oppert B, Morgan T, Hartzer K, and Kramer K. 2005. Compensatory proteolytic responses to dietary proteinase inhibitors in the red flour beetle, Tribolium castaneum (Coleoptera: Tenebrionidae). Comparative Biochemistry and Physiology 140C:53-58.

Oppert B, Morgan T, Hartzer K, Lenarcic B, Galesa K, Brzin J, Turk V, Yoza K, Ohtsubo K, and Kramer K. 2003. Effects of proteinase inhibitors on digestive proteinases and growth of the red flour beetle, Tribolium castaneum (Herbst)(Coleoptera: Tenebrionidae). Comparative Biochemistry and Physiology 134C:481-490.

Oppert B, Morgan TD, Culbertson C, and Kramer KJ. 1993. Dietary mixtures of cysteine and serine proteinase inhibitors exhibit synergistic toxicity toward the red flour beetle, Tribolium castaneum. Comparative Biochemistry and Physiology 105C:379-385.

Pimentel MA, D'A Faroni LR, Da Silva FH, Batista MD, and Guedes RNC. 2010. Spread of phosphine resistance among Brazilian populations of three species of stored product insects. Neotropical Entomology 39:101-107.

Pimentel MA, Faroni LR, Totola MR, and Guedes RN. 2007. Phosphine resistance, respiration rate and fitness consequences in stored-product insects. Pest Management Science 63:876-881.

Prabhakar, S, Chen, MS, Elpidina, EN, Vinokurov, KS, Smith, CM and Oppert, B. 2007. Molecular characterization of digestive proteinases and sequence analysis of midgut 
551

552

553

554

555

556

557

558

559

560

561

562

563

564

565

566

567

568

569

570

571

572

573

574

575

576

577

578

579

580

581

582

583

584

585

586

587

588

589

590

591

592

593

594

595

596

cDNA transcripts of the yellow mealworm, Tenebrio molitor L. Insect Molecular Biology 16:455-468.

Repnik U, Stoka V, Turk V, and Turk B. 2012. Lysosomes and lysosomal cathepsins in cell death. Biochimica et Biophysica Acta 1824:22-33.

Robinson SW, Herzyk P, Dow JA, and Leader DP. 2013. FlyAtlas: database of gene expression in the tissues of Drosophila melanogaster. Nucleic Acids Research 41:D744-750.

Schlipalius DI, Valmas N, Tuck AG, Jagadeesan R, Ma L, Kaur R, Goldinger A, Anderson C, Kuang J, Zuryn S, Mau YS, Cheng Q, Collins PJ, Nayak MK, Schirra HJ, Hilliard MA, and Ebert PR. 2012. A core metabolic enzyme mediates resistance to phosphine gas. Science 338:807-810.

Tamura K, Stecher G, Peterson D, Filipski A, and Kumar S. 2013. MEGA6: Molecular Evolutionary Genetics Analysis version 6.0. Molecular and Biological Evolution 30:2725-2729.

Terra WR, and Cristofoletti PT. 1996. Midgut proteinases in three divergent species of coleoptera. Computational Biochemistry and Physiology 113B:725-730.

Terra WR, and Ferreira C. 1994. Insect digestive enzymes: properties, compartmentalization and function. Computational Biochemistry and Physiology 109B:1-62.

Thompson, JD, Higgins DG, Gibson TJ. 1994. CLUSTAL W: Imporving the sensitivity of progressive multiple sequence alignment through sequence weighting, position-specific gap penalties and weight matrix choice. Nucleic Acid Research 22:4673-4680.

Tribolium Genome Sequencing Consortium, Richards S, Gibbs RA, Weinstock GM, Brown SJ, Denell R, Beeman RW, Gibbs R, Beeman RW, Brown SJ, Bucher G, Friedrich M, Grimmelikhuijzen CJ, Klingler M, Lorenzen M, Richards S, Roth S, Schroder R, Tautz D, Zdobnov EM, Muzny D, Gibbs RA, Weinstock GM, Attaway T, Bell S, Buhay CJ, Chandrabose MN, Chavez D, Clerk-Blankenburg KP, Cree A, Dao M, Davis C, Chacko J, Dinh H, Dugan-Rocha S, Fowler G, Garner TT, Garnes J, Gnirke A, Hawes A, Hernandez J, Hines S, Holder M, Hume J, Jhangiani SN, Joshi V, Khan ZM, Jackson L, Kovar C, Kowis A, Lee S, Lewis LR, Margolis J, Morgan M, Nazareth LV, Nguyen N, Okwuonu G, Parker D, Richards S, Ruiz SJ, Santibanez J, Savard J, Scherer SE, Schneider B, Sodergren E, Tautz D, Vattahil S, Villasana D, White CS, Wright R, Park Y, Beeman RW, Lord J, Oppert B, Lorenzen M, Brown S, Wang L, Savard J, Tautz D, Richards S, Weinstock G, Gibbs RA, Liu Y, Worley K, Weinstock G, Elsik CG, Reese JT, Elhaik E, Landan G, Graur D, Arensburger P, Atkinson P, Beeman RW, Beidler J, Brown SJ, Demuth JP, Drury DW, Du YZ, Fujiwara H, Lorenzen M, Maselli V, Osanai M, Park Y, Robertson HM, Tu Z, Wang JJ, Wang S, Richards S, Song H, Zhang L, Sodergren E, Werner D, Stanke M, Morgenstern B, Solovyev V, Kosarev P, Brown G, Chen HC, Ermolaeva O, Hlavina W, Kapustin Y, Kiryutin B, Kitts P, Maglott D, Pruitt K, Sapojnikov V, Souvorov A, Mackey AJ, Waterhouse RM, Wyder S, Zdobnov EM, Zdobnov EM, Wyder S, Kriventseva EV, Kadowaki T, Bork P, Aranda M, Bao R, Beermann A, Berns N, Bolognesi R, Bonneton F, Bopp D, Brown SJ, Bucher G, Butts T, Chaumot A, Denell RE, Ferrier DE, Friedrich M, Gordon CM, Jindra M, Klingler M, Lan Q, Lattorff HM, Laudet V, von Levetsow C, Liu Z, Lutz R, Lynch JA, da Fonseca RN, Posnien N, Reuter R, Roth S, Savard J, Schinko JB, Schmitt C, Schoppmeier M, Schroder R, Shippy TD, Simonnet F, Marques-Souza H, Tautz D, Tomoyasu Y, Trauner J, Van der Zee M, Vervoort M, Wittkopp N, Wimmer EA, Yang X, Jones AK, Sattelle DB, Ebert PR, Nelson D, Scott JG, Beeman RW, Muthukrishnan S, Kramer KJ, Arakane 
597

598

599

600

601

602

603

604

605

606

607

608

609

610

611

612

613

614

615

616

617

618

619

620
Y, Beeman RW, Zhu Q, Hogenkamp D, Dixit R, Oppert B, Jiang H, Zou Z, Marshall J, Elpidina E, Vinokurov K, Oppert C, Zou Z, Evans J, Lu Z, Zhao P, Sumathipala N, Altincicek B, Vilcinskas A, Williams M, Hultmark D, Hetru C, Jiang H, Grimmelikhuijzen CJ, Hauser F, Cazzamali G, Williamson M, Park Y, Li B, Tanaka Y, Predel R, Neupert S, Schachtner J, Verleyen P, Raible F, Bork P, Friedrich M, Walden KK, Robertson HM, Angeli S, Foret S, Bucher G, Schuetz S, Maleszka R, Wimmer EA, Beeman RW, Lorenzen M, Tomoyasu Y, Miller SC, Grossmann D, and Bucher G. 2008. The genome of the model beetle and pest Tribolium castaneum. Nature 452:949-955.

Tryselius Y, and Hultmark D. 1997. Cysteine proteinase 1 (CP1), a cathepsin L-like enzyme expressed in the Drosophila melanogaster haemocyte cell line mbn-2. Insect Molecular Biololgy 6:173-181.

Turk B, Bieth JG, Bjork I, Dolenc I, Turk D, Cimerman N, Kos J, Colic A, Stoka V, Turk V. 1995. Regulation of the activity of lysosomal cysteine proteinases by $\mathrm{pH}$-induced inactivation and/or endogenous protein inhibitors, cystatins. Biological Chemistry 376:225-230.

Turk B, Turk D, and Turk V. 2000. Lysosomal cysteine proteases: more than scavengers. Biochimica Biophysica Acta 1477: 98-111.

Turk V, Stoka V, Vasiljeva O, Renko M, Sun T, Turk B, and Turk D. 2012. Cysteine cathepsins: from structure, function and regulation to new frontiers. Biochimica Biophysica Acta 1824:68-88.

Vinokurov KS, Elpidina EN, Zhuzhikov DP, Oppert B, Kodrik D, and Sehnal F. 2009. Digestive proteolysis organization in two closely related Tenebrionid beetles: red flour beetle (Tribolium castaneum) and confused flour beetle (Tribolium confusum). Archives of Insect Biochemistry and Physiology 70:254-279. 
622 Figure 1. Heat map of the relative expression cysteine peptidase genes across life stages of $T$.

623 castaneum. The data is the normalized expression level (RPKM) from three biological replicates.

624 Red and warm tones indicate high expression and blue and cool tones indicate low expression.

625 The gene loci identification is to the right of the heat map (see Table 1 and Supplemental Table

626 S2 for more information).

627

628 Figure 2. Line graphs grouping data by three different expression patterns of T. castaneum

629 cysteine peptidase genes. A) Pattern group one includes those genes with increased expression in

630 adult and larvae stages. B) Pattern group two includes those genes that are constitutively

631 expression across all life stages. C) Pattern group three includes those genes that have low to no

632 expression in all life stages. Y-axis shows normalized logarithmic RPKM values, transformed

633 from raw data $(\mathrm{n}=3)$. The standard deviation for each data point was low (Table S2). Dotted

634 grey line shows baseline for expression; data points above this level have increased expression

635 and data points below have reduced expression relative to all other genes in the data set.

636

637 Figure 3. Phylogenetic tree of $T$. castaneum cysteine peptidases, using the predicted protein 638 sequence. Maximum likelihood tree with 500 iterations of bootstrapping were used;

639 bootstrapping values are represented as a percentage (0-100) by each branch. Genes shaded in 640 red had increased relative expression in feeding stages; genes shaded in yellow were expressed

641 constitutively in all developmental stages; genes shaded in blue had comparatively low to no

642 expression. Genes with high ( $>400 \mathrm{RPKM})$ expression during feeding stages only are indicated

643 with an asterisk. The chromosome number where each gene is located is shown in parentheses. 
645 Figure 4. Phylogenetic relationship of cysteine peptidases in T. castaneum and the model insects

646 Drosophila melanogaster and Apis mellifera. Maximum likelihood tree with 500 iterations of

647 bootstrapping. Bootstrapping values are represented as a percentage (0-100) by each branch.

648 Shading represents expression patterns as in Figure 2, and the letter represents the general 649 cathepsin type. Genes with high (>400 RPKM) expression during feeding stages only are 650 indicated with an asterisk. T. castaneum aspartic protease protein was used as an outgroup. 651 Brackets denote groups with high (99\%) bootstrap values. D. melanogaster genes with high to 652 very high expression in the midgut, as defined by default parameters in FlyAtlas Anatomical 653 Expression Data larval vs. adult (FlyBase.org), are indicated with H (high) or VH (very high). 654

655 Figure 5. Phylogenetic relationship between T. castaneum and other coleopterans, Diabrotica 656 virgifera virgifera, Dendroctonus ponderosae, and Leptinotarsa decemlineata. The tree was 657 constructed using maximum likelihood with 500 iterations of bootstrapping. Bootstrapping 658 values are represented as a percentage (0-100) by each branch. Coloring represents expression 659 patterns as in Figure 2. Genes with high (>400 RPKM) expression during feeding stages only are 660 indicated with an asterisk. T. castaneum aspartic protease gene was used as an outgroup.

661 Branches with more than one cysteine peptidase gene and with high sequence similarity were 662 reduced to a single branch and noted with number of total genes in parentheses.

663

664 Figure 6. Venn diagram of the functional characterization based on pattern groups of 25 cysteine 665 peptidase genes and an associated pseudogene in T. castaneum. Genes within the red circle are 666 those most likely involved in digestion, either directly or when inhibitors are present. Genes 667 within the yellow circle are those most likely to be lysosomal or with ubiquitous function. Genes 
668 within the blue circle have low/no expression in our study. The genes that fall into multiple

669 categories are within the overlapping portions of the circles. Genes that were highly upregulated

670 when $T$. castaneum larvae were fed digestive inhibitors are marked with an asterisk. The most

671 highly expressed genes are showed in bold. The seven genes with a major role in digestion are 672 underlined. 
673 Table 1. Relative expression of cysteine cathepsin genes in four developmental stages $(\mathrm{n}=3)$ of $T$. castaneum, and the overall change in 674 expression in response to peptidase inhibitors (PIs) in the larval gut. Shaded entries have been annotated as "lysosomal" at NCBI.

\begin{tabular}{|c|c|c|c|c|c|c|c|c|c|c|c|}
\hline Gene ID & Protein ID & $\begin{array}{c}\text { Tc } \\
\text { Annotation' }\end{array}$ & Chromosome & $\begin{array}{c}\text { Larval Gut } \\
\text { Expression } \\
(\mathrm{RPKM})^{2}\end{array}$ & $\begin{array}{c}\text { Gut } \\
\text { Rank }^{3}\end{array}$ & Annotation $^{2}$ & $\begin{array}{c}\text { Adult } \\
\text { Expression } \\
\text { (RPKM) }\end{array}$ & $\begin{array}{c}\text { Egg } \\
\text { Expression } \\
(\mathbf{R P K M})\end{array}$ & $\begin{array}{c}\text { Larvae } \\
\text { Expression } \\
(\mathrm{RPKM})\end{array}$ & $\begin{array}{c}\text { Pupae } \\
\text { Expression } \\
(\mathrm{RPKM})\end{array}$ & $\begin{array}{c}\text { Response to } \\
\text { PIs }^{4}\end{array}$ \\
\hline LOC659441 & NP_001164001 & 11001 & 10 & 77,200 & 82 & $\mathrm{~L}$ & 3,844 & 0.50 & 55,588 & 11.2 & 3 -fold increase \\
\hline LOC659502 & NP_001164314 & 11000 & 10 & 25,900 & 14 & $\mathrm{~L}$ & 6,392 & 0.03 & 13,551 & 1.90 & 7 -fold increase \\
\hline LOC6592265 & XP_970644 & 11003 & 10 & 42.8 & 7 & L & 817 & 734 & 878 & 26.4 & none \\
\hline LOC6593675 & XP_970773 & 11002 & 10 & 35.1 & 2 & L homolog & 42.9 & 0.03 & 24.0 & 0.03 & none \\
\hline LOC659565 & XP_970951 & 10999 & 10 & 0.28 & 2 & L & 3.82 & 5.75 & 0.15 & 1.54 & 3 -fold decrease \\
\hline LOC660368 & XP_971698 & 09365 & 7 & 2,390 & 44 & $\mathrm{~L}$ & 489 & 0.16 & 1,866 & 0.03 & 2-fold increase \\
\hline LOC660551 & XP_971867 & 09362 & 7 & 1.99 & 1 & $\mathrm{~L}$ & 0.61 & 0.03 & 0.42 & 0.03 & none \\
\hline LOC660428 & XP_971752 & 09364 & 7 & 0.98 & 1 & $\mathrm{~L}$ & 8.29 & 0.13 & 0.03 & 0.03 & none \\
\hline LOC660669 & XP_971975 & 09448 & 7 & 0.02 & 2 & $\mathrm{~L}$ & 7.77 & 0.10 & 0.89 & 0.08 & none \\
\hline $\begin{array}{l}\text { LOC663234 } \\
(26-29-p)\end{array}$ & NP_001164088 & 09486 & 7 & 1,310 & NOC & $\mathrm{L}$ & 233 & 324 & 287 & 818 & none \\
\hline LOC660491 & NC_007422 & pseudogene & 7 & - & $\mathrm{NOC}$ & L & 0.03 & 0.03 & 0.03 & 0.03 & - \\
\hline LOC656198 & XP_967834 & 09217 & 7 & 28.6 & 1 & B homolog & 35.9 & 25.2 & 44.5 & 4.04 & - \\
\hline LOC662417 & XP_973607 & --- & 7 & 2.32 & NOC & F & 57.9 & 18.7 & 42.7 & 5.30 & - \\
\hline LOC663145 & XP_974298 & 02952 & 3 & 3,140 & 43 & B & 669 & 0.57 & 1690 & 1.47 & 7-fold increase \\
\hline LOC663117 & NP_001164205 & 02953 & 3 & 1,130 & 46 & B & 65.6 & 0.03 & 162 & 4.42 & none \\
\hline LOC663090 & XP_974244 & 02954 & 3 & 249 & 9 & B & 93.3 & 0.11 & 148 & 0.54 & 2-fold decrease \\
\hline LOC663066 & XP_974220 & 02955 & 3 & 79.9 & 2 & B-like & 337 & 188 & 372 & 14.6 & 2-fold decrease \\
\hline LOC658343 & XP_969833 & 02843 & 3 & 0.02 & 1 & L & 0.36 & 0.10 & 0.03 & 0.03 & none \\
\hline LOC6551485 & XP_966750 & 05431 & 8 & 443.27 & 3 & B-like & 112 & 0.13 & 59.5 & 0.03 & 5-fold decrease \\
\hline LOC655077 & XP_966663 & 05432 & 8 & 1.18 & 3 & B-like & 0.10 & 0.03 & 0.03 & 0.03 & 4-fold decrease \\
\hline LOC657117 & XP_968689 & 05954 & 8 & 57.6 & NOC & B homolog & 9.14 & 0.03 & 1.65 & 0.33 & 18 -fold increase \\
\hline LOC657203 & XP_968767 & 05953 & 8 & 82.2 & 3 & B-like & 4.16 & 0.03 & 10.8 & 0.03 & 20 -fold increase \\
\hline LOC656957 & XP_008196467 & $05955 / 05956$ & 8 & - & NOC & B-like & 9.87 & 0.03 & 0.64 & 0.08 & 4-fold increase \\
\hline LOC657038 & XP_008196465 & ; $\quad--$ & 8 & - & NOC & B-like & 0.03 & 0.03 & 0.03 & 0.03 & - \\
\hline LOC659087 & XP_970512 & 07214 & 4 & 12.0 & $\mathrm{NOC}$ & $\mathrm{O}$ & 36.1 & 35.3 & 15.4 & 115 & 1.3 decrease \\
\hline LOC100141668 & XP_001814509 & 13582 & $1(\mathrm{X})$ & 0 & 1 & $\mathrm{~K}$ & 1.24 & 0.03 & 0.10 & 0.03 & - \\
\hline
\end{tabular}




\section{$681 \quad \underline{\text { Figure } 1 .}$}

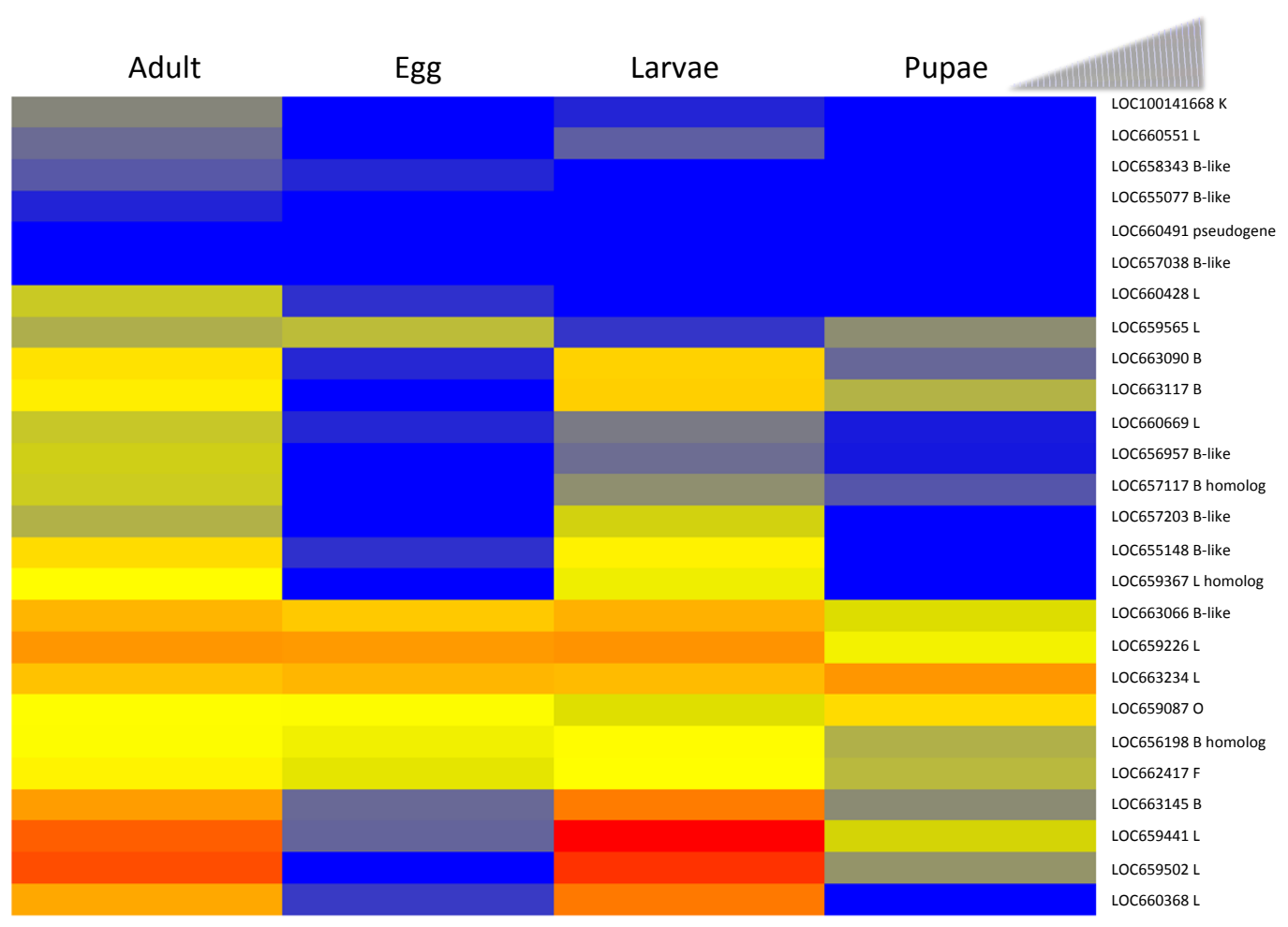

682

683 
685 Figure 2.

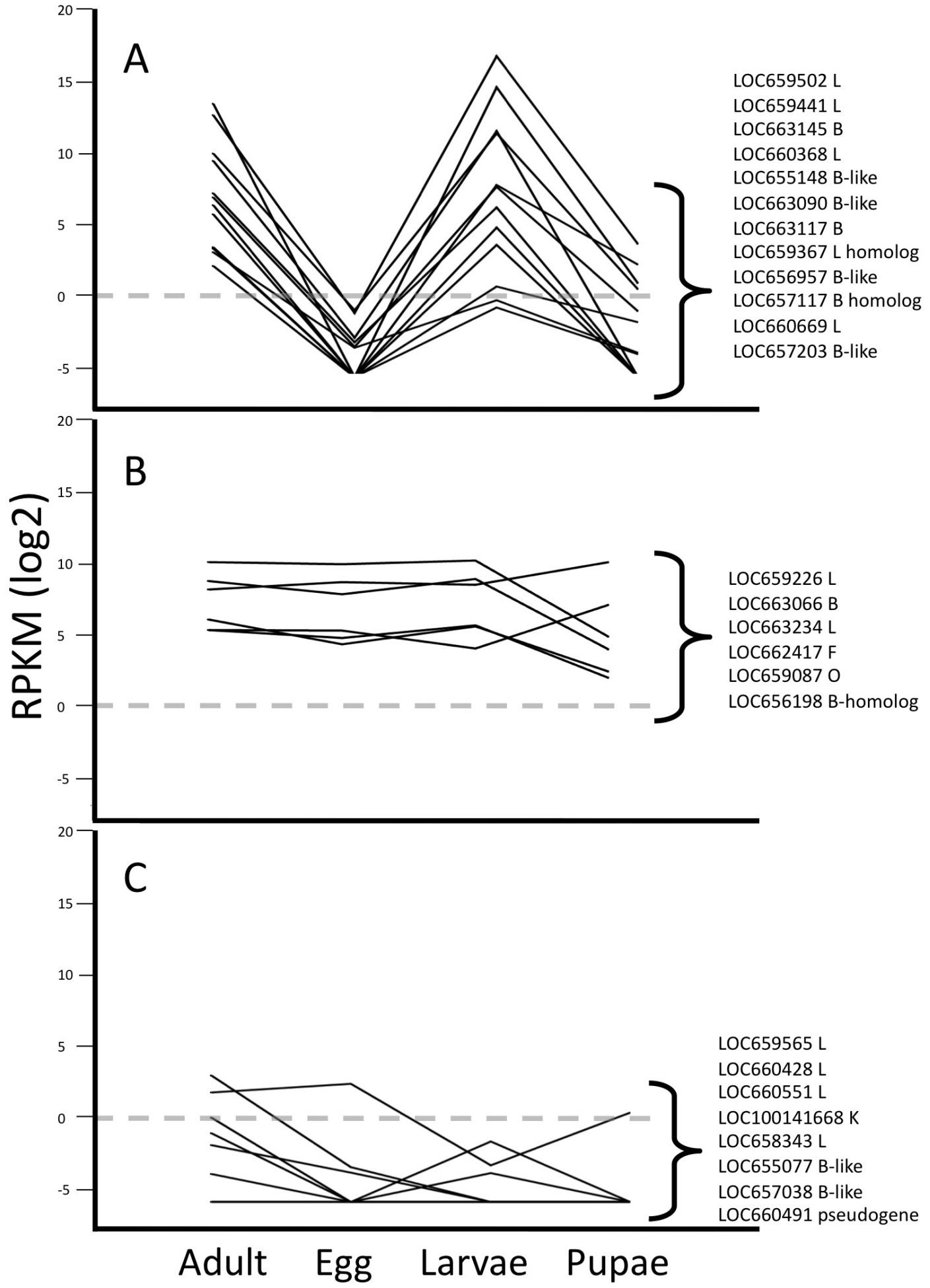

686

687 
689 Figure 3.

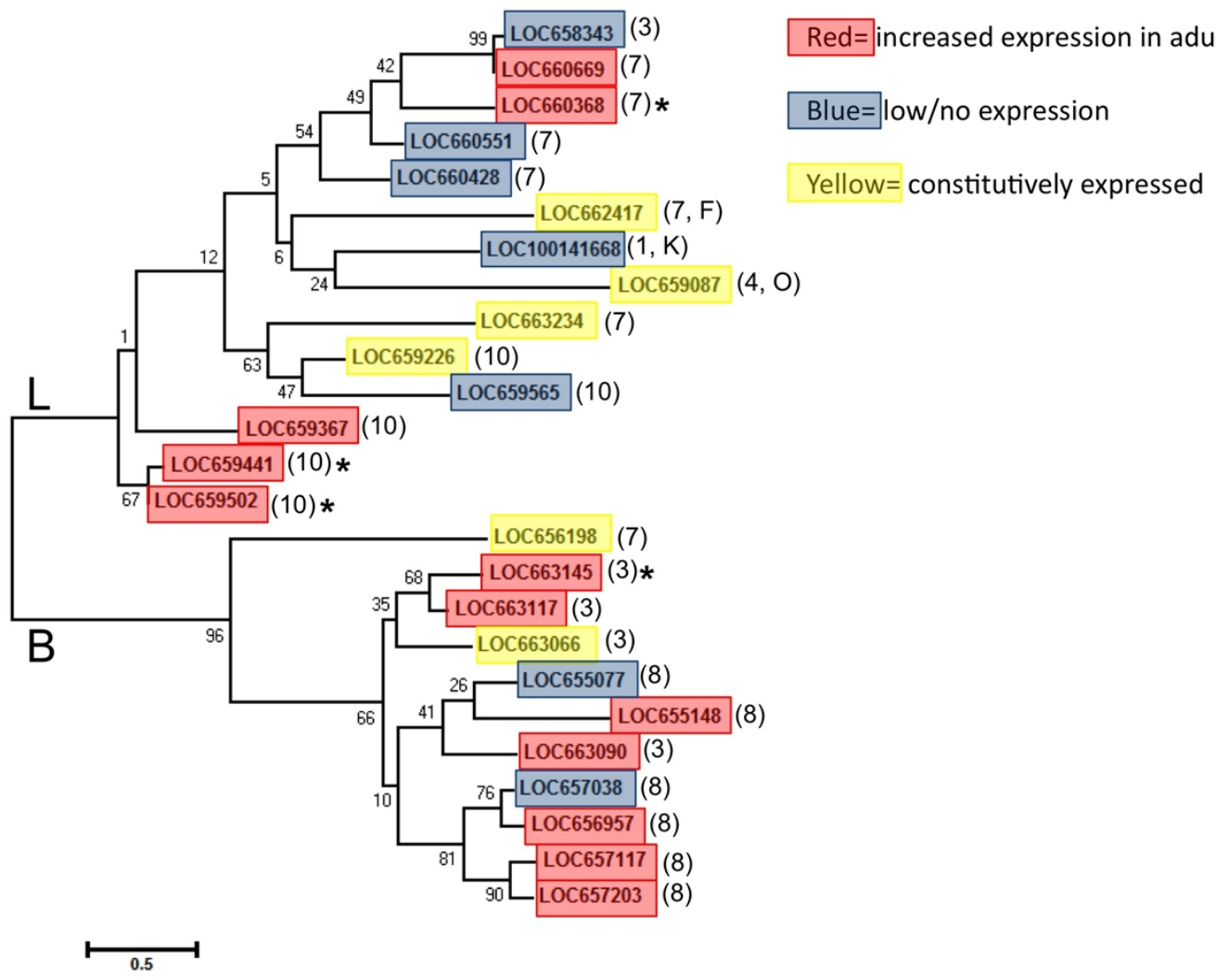




\section{Figure 4.}

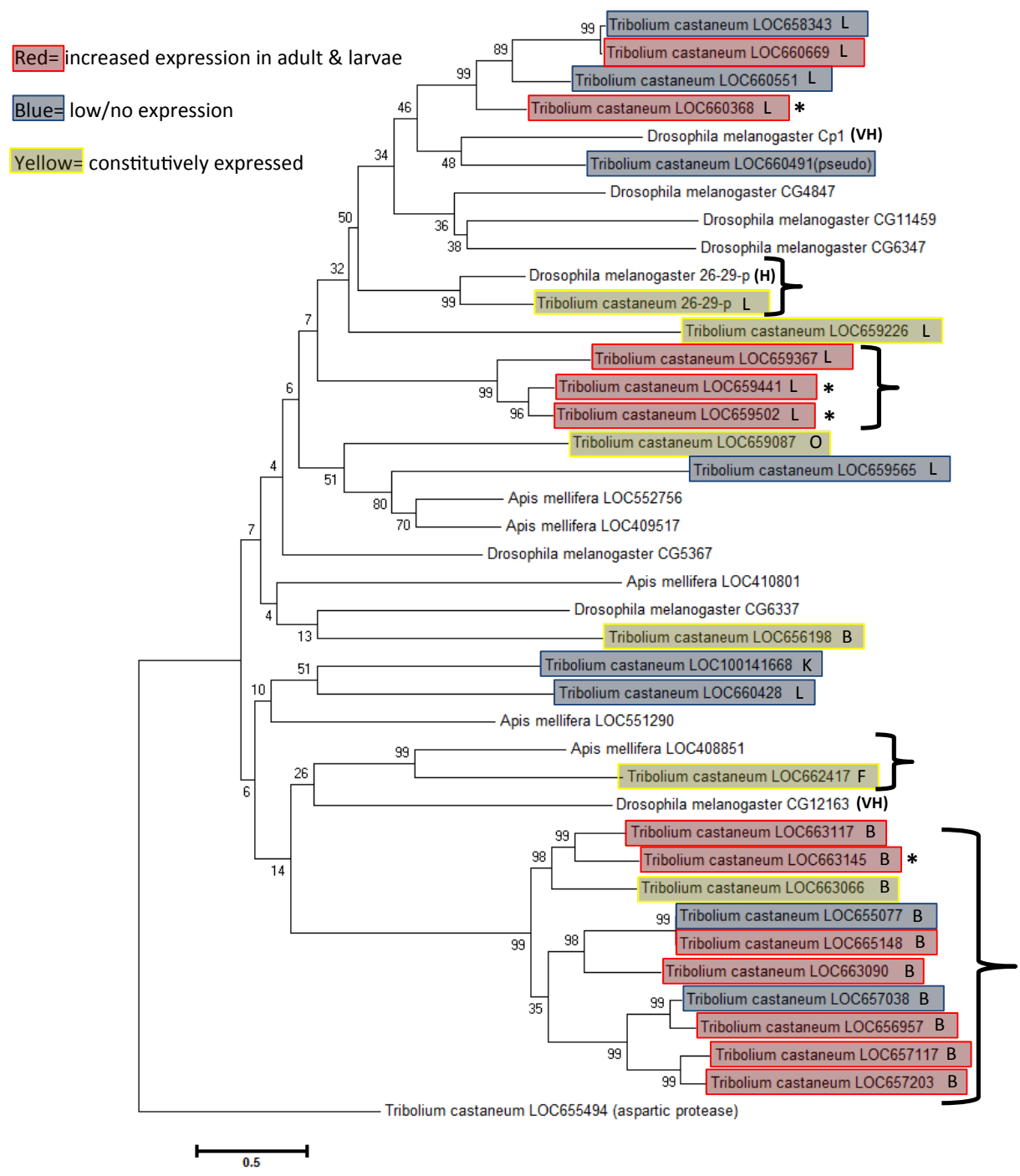

693 


\section{$695 \quad$ Figure 5.}

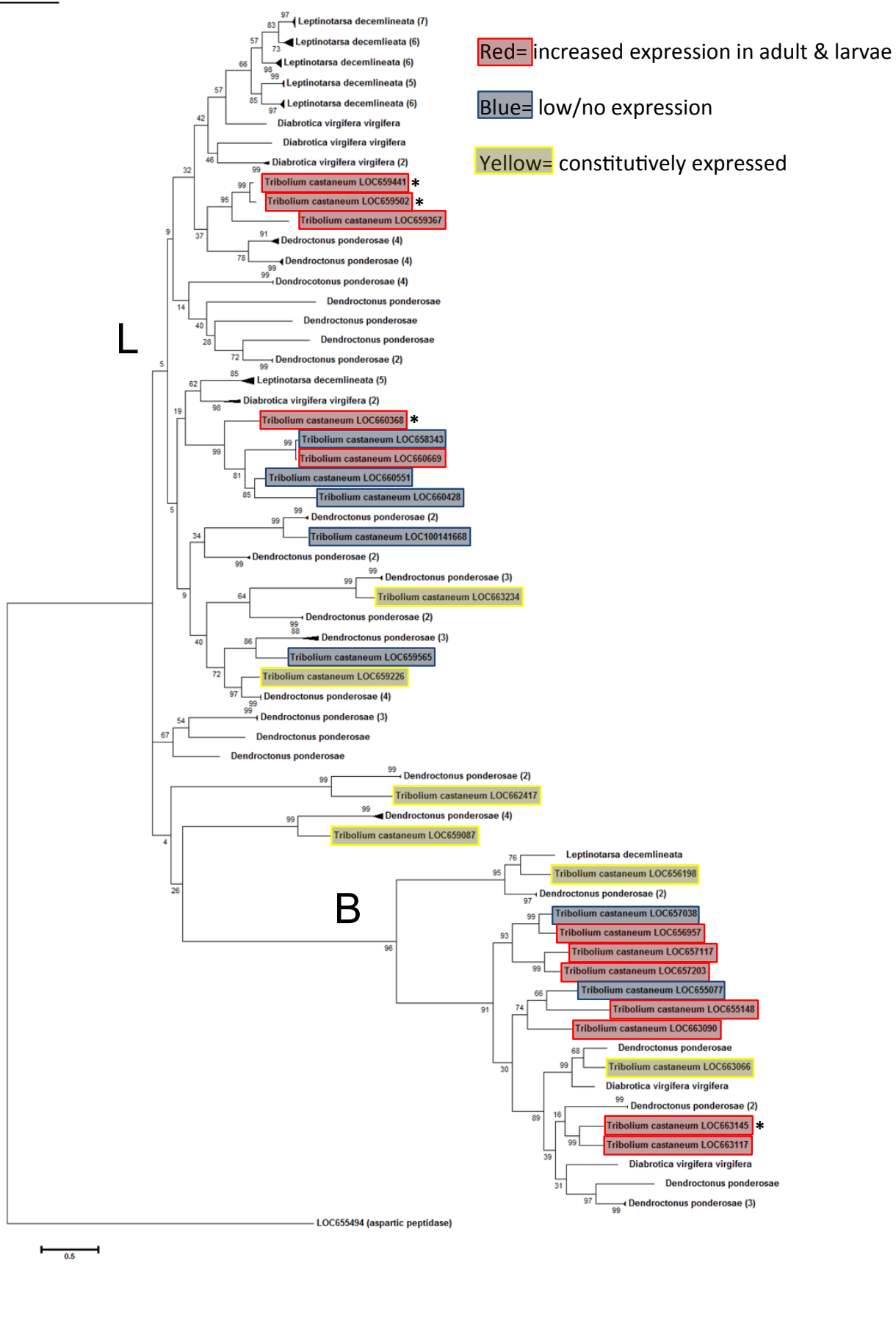


699 Figure 6.

700

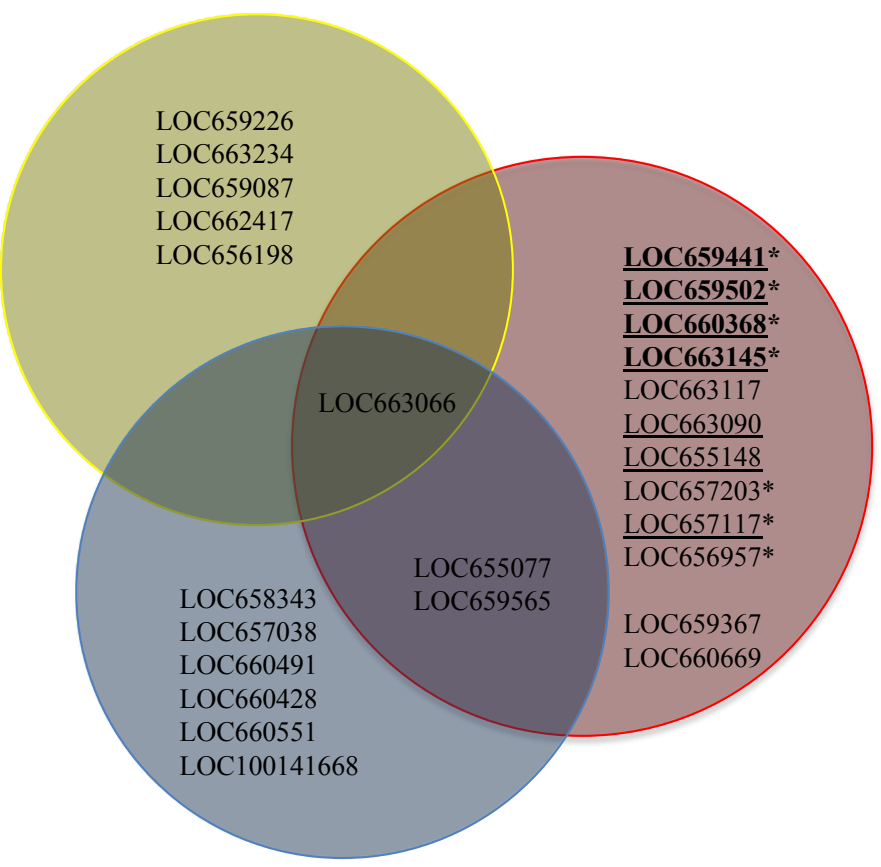

